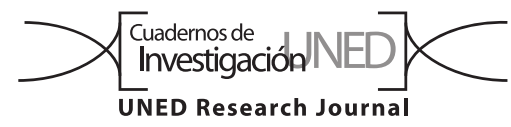

\title{
Composición de la comunidad, estructura poblacional y condición reproductiva de roedores en una granja avícola de Costa Rica
}

\author{
Javier Monge ${ }^{1,2}$ \& Carol Sánchez ${ }^{1}$ \\ 1. Centro de Investigación en Protección de Cultivos, Escuela de Agronomía, Universidad de Costa Rica; javier.monge@ucr.ac.cr, \\ carol.sancheznunez@ucr.ac.cr \\ 2. Instituto de Investigaciones Agrícolas, Facultad de Ciencias Agroalimentarias, Universidad de Costa Rica.
}

Recibido 07-II-2018 • Corregido 14-III-2018 • Aceptado 28-IV-2018

\begin{abstract}
Community composition, population structure and reproductive status of rodents in a poultry farm in Costa Rica. Rodents are usually part of livestock production systems. Due to the negative impact they caused it is necessary to implement control programs by determining the species and population status. We studied the rodent community in a poultry farm: Fabio Baudrit Moreno Agricultural Experiment Station, University of Costa Rica, located in La Garita, Alajuela, Costa Rica. During 25 months we made fortnightly samplings in two consecutive periods of 24 hours each, with snap traps in 53 fixed stations located around the sheds and warehouses. We collected three species of rodents: house mouse (Mus musculus, $\mathrm{n}=115$ ), field rat (Sigmodon hirsutus, $\mathrm{n}=9$ ) and Norway rat (Rattus norvegicus, $\mathrm{n}=6$ ). The population structure of $M$. musculus was defined by a sex ratio of 1,9:1 and a predominance of adults. The $44 \%$ of the captured females were pregnant. The litter size ranged from 3 to 7 embryos, with an average of 5,17 embryos / litter. The period of greatest reproductive activity was between June and September.
\end{abstract}

Key words: Mus musculus, Sigmodon hirsutus, Rattus norvegicus, pest rodents, poulatry farm.
RESUMEN: Los roedores por lo general forman parte de los sistemas de producción pecuaria. Dado el impacto negativo que provocan, se requiere implementar programas de control al determinar las especies y el estado de sus poblaciones. Estudiamos la comunidad de roedores en la granja avícola de la Estación Experimental Agrícola Fabio Baudrit Moreno, de la Universidad de Costa Rica, ubicada en La Garita de Alajuela, Costa Rica. Durante 25 meses hicimos muestreos quincenales, en dos periodos consecutivos de 24 horas cada uno, utilizándose trampas de golpe grandes en 53 estaciones fijas ubicadas en los alrededores de los galpones y bodegas. Se colectaron tres especies de roedores, el ratón casero (Mus musculus, $\mathrm{n}=115$ ), la rata de campo (Sigmodon hirsutus, $n=9$ ) y la rata gris o de caño (Rattus norvegicus, $n=6$ ). La estructura poblacional de $M$. musculus estuvo definida por una proporción de sexos de 1,9:1 (machos y hembras) y un predominio de adultos. El $44 \%$ de las hembras capturadas se encontraban preñadas, con tamaños de camadas entre 3 y 7 embriones, y un promedio de 5,17 embriones/camada. La época de mayor actividad reproductiva fue entre los meses de junio y setiembre.

Palabras clase: Mus musculus, Sigmodon hirsutus, Rattus norvegicus, roedores plaga, granja avícola.
La presencia de roedores puede afectar las actividades pecuarias, ya sea por el consumo y contaminación de alimentos destinados a los animales, depredación de animales o subproductos como huevos, transmisión de enfermedades a los animales domésticos y personas, u ocasionando daños en infraestructura y equipos (Elias \& Fall, 1988a; Gratz, 1994; Gómez, Miñarro, Ribicich, Rossetti, Rossotti \& Buchs, 2004).

Entre las especies de roedores más frecuentemente encontradas en ambientes pecuarios se encuentra la rata negra (Rattus rattus), rata gris o de caño (Rattus norvegicus) y el ratón casero o bodeguero (Mus musculus), especies de distribución cosmopolita y que ocupan una gran variedad de hábitats. El ratón casero alcanza sus máximas densidades en los ambientes urbanos, aunque pueden presentar incrementos poblacionales importantes en campos agrícolas y en bosques (Ylönen, Jacob, Davies \& Singleton, 2002; Ruscoe, Wilson, McElrea \& Richardson, 2004). Su presencia en áreas de cultivo y bordes se considera ocasional, aunque puede llegar a ser abundantes en sistemas de producción cerrados (León, Guidobono \& Busch, 2007). La existencia de poblaciones de roedores, específicamente de $M$. musculus en granjas avícolas es común, cuyo grado de infestación es influenciado por las 
medidas de mantenimiento de la granja y los galpones, así como el grado de aplicación de medidas de control (Gómez, Bilenca, Cavia, Mino, Cattadino \& Busch, 2001; Gómez, Cavia, Busch \& Bilenca, 2003; Gómez, Miñarro, Valenzuela \& Bilenca, 2009). En las granjas avícolas, esta especie puede alcanzar altas abundancias, debido a la alta disponibilidad de alimento y las condiciones de temperatura y humedad beneficiosas que le permiten reproducirse durante todo el año, aunado a una menor abundancia de especies competidoras (León et al., 2007).

La rata gris (R. norvegicus) al igual que el ratón casero es común en ambientes urbanos, aunque también ha resultado ser abundante en granjas avícolas (Villa, Whisson \& Sánchez-Cordero, 1997; Gómez et al., 2004; Gómez \& Busch, 2007), mientras que en otros estudios reportan a la rata negra ( $R$. rattus) como la especie predominante (Parshad, Ahmad \& Chopra, 1987; Sridhara \& Krishnamurthy, 1992; Kandhwal, 2009).

La identificación de especies dañinas presentes en un área de producción es necesario para diseñar programas de control. A su vez, aquellos aspectos que influyan la dinámica poblacional, tales como la estructura poblacional y la condición reproductiva de los individuos también son importantes. Según sea la estructura poblacional, se puede deducir si la misma está creciendo, decreciendo o se mantiene estable. De igual manera, la condición reproductiva, es decir la actividad o inactividad reproductiva de los individuos, permite determinar las tendencias de la población. La necesidad de investigación sobre el problema de roedores en actividades pecuarias en Costa Rica es evidente, debido a la poca información documentada, lo cual queda limitada al aporte de Wing Ching-Jones, Monge-Meza \& Pérez-Salas (2009) en un módulo lechero.

El presente estudio se realizó con el propósito de determinar las especies de roedores presentes en una granja avícola, así como la estructura poblacional y la condición reproductiva de las especies presentes.

\section{MATERIALES Y MÉTODOS}

El estudio se desarrolló en la granja avícola de la Estación Experimental Fabio Baudrit Moreno (EEAFBM) de la Universidad de Costa Rica (UCR) ubicada en La Garita de Alajuela $\left(10^{\circ} 01^{\prime} \mathrm{N}\right.$ y $\left.84^{\circ} 16^{\prime} \mathrm{W}\right)$ a una altitud de $840 \mathrm{msnm}$. El sitio se caracteriza por una temperatura promedio anual de $23,3^{\circ} \mathrm{C}, 6,6$ horas de brillo solar, una precipitación anual de $1745,4 \mathrm{~mm}$ y una humedad relativa de $79 \%$ (IMN, s.f.).
El muestreo de roedores se realizó durante 25 meses (mayo de 2011 a julio de 2013). Los muestreos fueron quincenales con dos periodos de 24 horas consecutivas, colocándose las trampas entre las 0700-0800 horas y revisándose 24 horas después. En cada muestreo se colocaron 53 trampas, para un total de 6148 trampas-día. Las trampas se colocaron alrededor de los galpones y otras infraestructuras (bodegas), en estaciones fijas para todos los muestreos.

Para los muestreos se utilizaron trampas grandes de golpe $(17 \times 8,5 \mathrm{~cm})$, marca Victor ${ }^{\circ}$ y como cebo atrayente un trozo de coco de aproximadamente $1 \mathrm{~cm}^{3}$. Para el segundo día de muestreo, los cebos fueron cambiados para mantener las mismas condiciones entre muestreos.

Los especímenes capturados fueron medidos, pesados y se le tomaron datos de estado reproductivo; en el caso de los machos, se observó la posición de los testículos, ya sea escrotal o abdominal, y se usó como criterio de la condición reproductiva, donde los individuos con testículos escrotales se clasificaron como activos reproductivamente (Singleton, 1985). Para las hembras, se usó como criterio el estado de preñez, para clasificarlas como activamente reproductivas. Cuando las hembras estaban preñadas se hizo un conteo de embriones.

Para clasificar a los individuos según su edad, para $M$. musculus se utilizó el peso corporal según la clasificación de Chou, Lee, Lu y Yu (1998), la cual contempla cuatro categorías: I) peso menor a 9g, II) de 9 a 11,9g, III) de 12 a $14,9 \mathrm{~g}$ y IV) igual o más de $15 \mathrm{~g}$. Para Sigmodon hirsutus se usó como criterio el peso corporal según la clasificación sugerida por Monge (2008), considerándose jóvenes los individuos con peso menor a 57,2 g, adultos jóvenes entre 57,3 y $113 \mathrm{~g}$ y adultos viejos con peso superior a $113 \mathrm{~g}$. Para R. norvegicus se usó la referencia de Villa et al. (1997) quienes colectaron hembras preñadas a partir de la clase de peso de 101-200g., lo cual indica que las hembras dentro de este ámbito de peso disponen de madurez sexual, es decir, se pueden clasificar como adultos, criterio complementado con el usado por Bishop y Hartley (1976) también basado en el peso corporal, quienes establecen una relación entre peso y edad, en donde a los 3 meses alcanzan o superan los $100 \mathrm{~g}$ y Greaves (1984) que esta especie alcanza la madurez entre las 12 y 16 semanas de edad.

\section{RESULTADOS}

Especies de roedores capturadas y distribución de capturas en el tiempo: Durante el período de estudio se colectaron tres especies de roedores. La especie predominante fue el ratón casero (Mus musculus) con un total 
de 115 individuos (88,46\%), seguido por la rata de campo (Sigmodon hirsutus) con 9 individuos $(6,92 \%)$ y la rata gris (Rattus norvegicus) con 6 individuos (4,62\%).

En el primer año de muestreo (2011) la cantidad de capturas de $M$. musculus fue de 81 individuos, lo que representa el $70,43 \%$ de las capturas totales del estudio. Los meses con mayor cantidad de capturas fueron agosto y setiembre, con un total de 17 individuos por mes. Para los meses de mayo a octubre de 2011, la cantidad de capturas osciló entre 9 y 11 individuos, mostrándose una baja en los meses de noviembre y diciembre con solo 3 individuos en cada mes (Fig. 1).

En enero y febrero del 2012 no hubo capturas, iniciándose en marzo un nuevo período de capturas que se extendió hasta setiembre, pero con una cantidad de capturas menor a la mitad de las logradas en el primer año, con solo 33 individuos. Al igual que el año anterior, al final del año y principios del siguiente, correspondiente a la época seca en el sitio, se observó una ausencia de capturas. Para el siguiente año (2013) las capturas se inician de igual manera en el mes de marzo, con solo una captura, la cual fue la única hasta el final del período de muestreo, en julio de 2013.

Para la rata de campo, en el 2011 se logró dos capturas, en mayo y en agosto, mientras que las otras siete fueron en el 2012, en los meses de enero (dos capturas), mayo (una captura), junio (tres capturas) y octubre (una captura). Las colectas de la rata gris, se hicieron en los meses de julio (una captura) y noviembre (dos capturas) del 2011, así como dos en el mes de enero y una en agosto del 2012.
Estructura poblacional y condición reproductiva de Mus musculus: De los 115 individuos de M. musculus, 112 se logró clasificar por sexo, presentándose un predominio de capturas de machos, con un total de 73 individuos, y 39 hembras, para una proporción de 1,9:1 (machos:hembras). Esta proporción fue más marcada durante el primer año, con una relación 2,1:1, mientras que para el segundo año fue de 1,4:1. En prácticamente todos los meses hubo representación de ambos sexos en las muestras, evidenciándose en algunos un predominio importante a favor de los machos, como lo fue en los meses de julio y octubre de 2011 (Fig. 1).

Con respecto a la clasificación de los individuos por clase de edad, basado en el peso corporal, para los machos se observa un predomino de las clases II y III, con 27 individuos (37\%) y $32(44 \%)$ respectivamente. Para las hembras, hay una mayor representación en las clases III y IV, con 14 (36\%) y 19 (49\%) individuos. Dado que el peso corporal es influenciado por el estado de preñez, si solo se considera las hembras no preñadas, la proporción de hembras de la clase III sería de $41 \%$ y la clase IV se reduce a 36\% (Cuadro 1).

En cuanto a la representación de las clases de edad a través del tiempo, la tendencia es encontrar representación de las clases II, III y IV, tanto para los machos como para las hembras. En el caso de la clase I, correspondiente a los más jóvenes, solo estuvo representada por dos individuos machos, colectados en los meses de junio y julio de 2011, lo que sugiere el período en que ocurren los nacimientos.

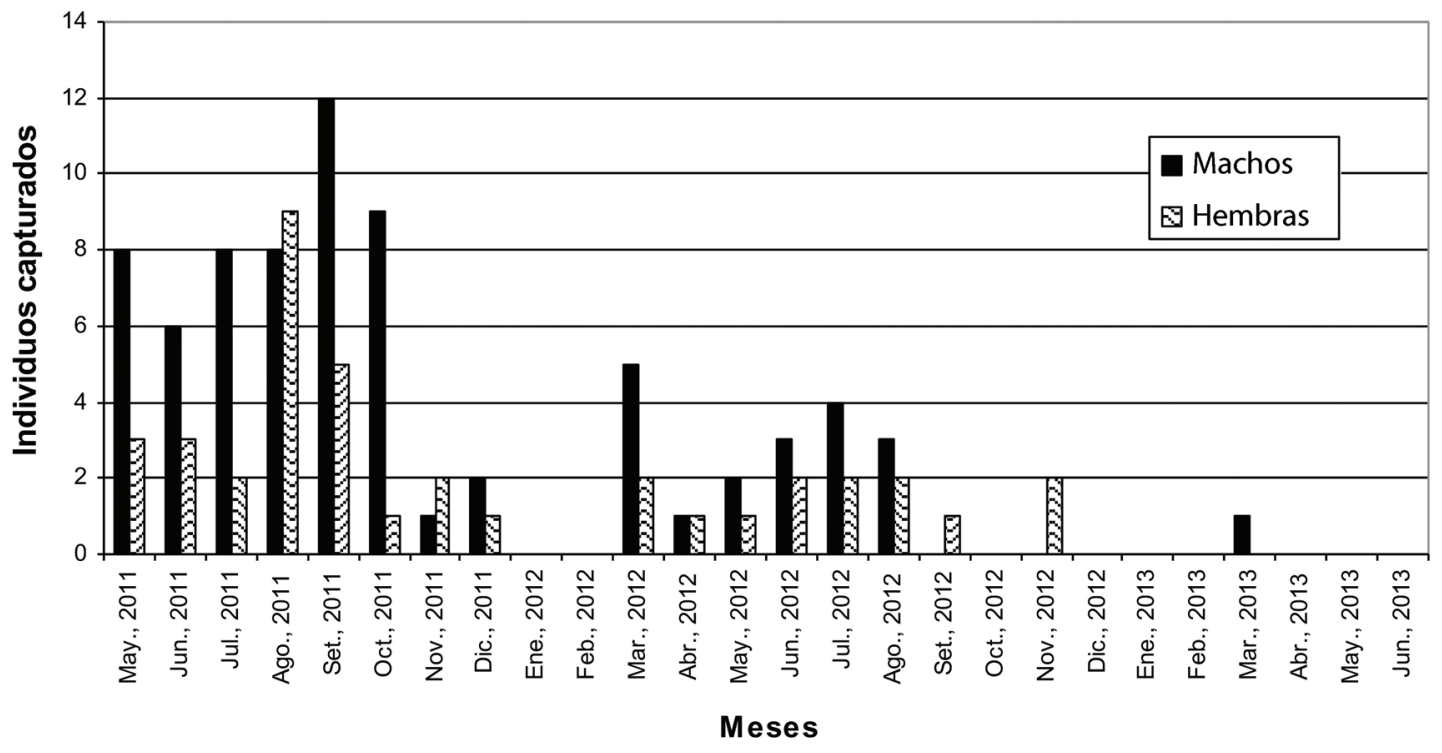

Fig. 1. Capturas por mes de M. musculus, en la granja avícola de la EEAFBM, Alajuela, Costa Rica. 


\section{CUADRO 1}

Proporción de machos y hembras e individuos activamente reproductivos de M. musculus, según clase de edad basada en el peso corporal, en la granja avícola de la EEAFBM, Alajuela, Costa Rica.

\begin{tabular}{cccccc} 
Clase de edad & Ámbito de peso $(\mathrm{g})$ & Machos & Hembras & Machos con testículos escrotales & Hembras preñadas \\
I & $<9$ & 2 & 0 & 0 & 0 \\
II & $9,0-11,9$ & 27 & 6 & 12 & 1 \\
III & $12,0-14,9$ & 32 & 14 & 18 & 5 \\
IV & $\geq 15$ & 12 & 19 & 6 & 11 \\
Total & & 73 & 39 & 36 & 17 \\
\hline
\end{tabular}

En cuanto a la actividad reproductiva de $M$. musculus se observó en individuos de las clases II, III y IV para ambos sexos. De los machos adultos, se encontró una similitud en la proporción de individuos en actividad e inactividad reproductiva, con 36 y 35 individuos, respectivamente. De los 27 individuos ubicados en la clase de edad II, el $44 \%$ se encontraba en condición reproductiva; de la clase de edad III, el 56\% y 18 de la clase IV, el 50\%.

Con respecto a la actividad reproductiva de las hembras, 17 (44\%) de las 39 hembras se encontraban preñadas en el momento de la captura. La mayoría de las hembras preñadas fueron clasificadas en las clases de edad III y IV; sin embargo, una de ellas pertenece a la clase II. La captura de hembras preñadas ocurrió en los meses de julio a diciembre de 2011, excepto en el mes de noviembre. Posteriormente se lograron capturas de hembras preñadas en julio y agosto del 2012. Los meses con más hembras preñadas fueron agosto y setiembre de 2011, con 5 hembras preñadas en cada mes. Los tamaños de camada en este estudio, oscilaron entre 3 y 7 embriones, con un promedio de 5,17 $\pm 1,29$ crías por camada.

Al considerar la actividad reproductiva mostrada por machos y hembras, los meses de mayor actividad reproductiva fueron julio y agosto para los machos y de julio y setiembre para las hembras, aunque en meses previos y posteriores se mostró actividad reproductiva. Podría definirse un período de mayor reproducción para la población de M. musculus para el sitio de estudio, de junio a setiembre (Cuadro 2), lo cual coincide con el período de captura de los dos juveniles.

CUADRO 2

Capturas de M. musculus adultos y proporción de individuos activamente reproductivos durante los meses de mayo de 2011 a junio de 2013. Los meses que no aparecen, se debe a que no hubo capturas de esta especie.

\begin{tabular}{|c|c|c|c|c|}
\hline Mes & Machos (n) & Machos con testículos escrotales (\%) & Hembras (n) & Hembras preñadas (\%) \\
\hline \multicolumn{5}{|c|}{ 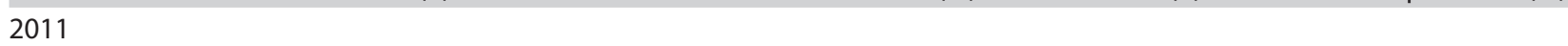 } \\
\hline Mayo & 8 & 25 & 3 & 0 \\
\hline Junio & 5 & 60 & 3 & 0 \\
\hline Julio & 7 & 87,5 & 2 & 100 \\
\hline Agosto & 8 & 87,5 & 9 & 55,6 \\
\hline Setiembre & 12 & 16,7 & 5 & 100 \\
\hline Octubre & 9 & 33,3 & 1 & 100 \\
\hline Noviembre & 1 & 0 & 2 & 0 \\
\hline Diciembre & 2 & 100 & 1 & 100 \\
\hline \multicolumn{5}{|l|}{2012} \\
\hline Marzo & 5 & 60 & 2 & 0 \\
\hline Abril & 1 & 100 & 1 & 0 \\
\hline Mayo & 2 & 0 & 1 & 0 \\
\hline Junio & 3 & 66,7 & 2 & 0 \\
\hline Julio & 4 & 75 & 2 & 100 \\
\hline Agosto & 3 & 33,3 & 2 & 50 \\
\hline Setiembre & & & 1 & 0 \\
\hline Noviembre & & & 2 & 0 \\
\hline \multicolumn{5}{|l|}{2013} \\
\hline Marzo & 1 & 100 & & \\
\hline Total & 71 & 50,7 & 39 & 43,6 \\
\hline
\end{tabular}


Estructura poblacional y condición reproductiva de Sigmodon hirsutus: Con respecto a la rata de campo (Sigmodon hirsutus) de los nueve individuos capturados, cinco eran machos, para una proporción de 1,25:1 (machos:hembras). En cuanto a la estructura poblacional, se tiene dos hembras jóvenes y dos hembras adultas jóvenes, mientras que los machos, dos fueron clasificados como adultos jóvenes y tres como adultos viejos. En lo referente a la actividad reproductiva, ninguna hembra se encontraba en estado de preñez, y de los machos solo uno mostraba testículos escrotales, el cual corresponde al individuo capturado en octubre de 2012.

Estructura poblacional y condición reproductiva de Rattus norvegicus: De la rata gris (Rattus norvegicus) se capturó un total de seis individuos, de los cuales cuatro eran hembras. Dos capturas se realizaron en el mes de noviembre de 2011 y otras dos en enero del 2012, lo que concentra la mayoría de las capturas para la época seca entre 2011 y 2012. Solo una de las hembras estaba preñada, con un total de 9 embriones, cuya captura se realizó en agosto de 2012.

\section{DISCUSIÓN}

En este estudio se colectaron tres especies de roedores dentro de un área relativamente pequeña de aproximadamente 0,5 ha, en donde se encuentran instalaciones dedicadas a la producción avícola, lo que constituye un complejo de especies de roedores, aún cuando una de ellas fue evidentemente predominante con una representación cercana al $90 \%$ de las capturas. Esta situación de presencia de varias especies ha sido encontrado en otros estudios (Gómez et al., 2001; Gómez et al., 2003; Miño, Cavia, Gómez, Bilenca, \& Busch, 2007), así como casos en que $M$. musculus ha mostrado un predominio en granjas avícolas con respecto a otras especies presentes (León et al., 2007; Gómez et al., 2009).

La mayor abundancia de $M$. musculus puede deberse a que los requerimientos de esta especie sean comparativamente menores a los de las otras dos especies colectadas. Así, por ejemplo, en cuanto a las necesidades de alimento, dado el menor tamaño de M. musculus, cuyo peso oscila entre 15 y $25 \mathrm{~g}$, comparado con $R$. norvegicus, con pesos entre 150 y $600 \mathrm{~g}$ (Greaves, 1984), para M. musculus basta con un consumo diario de 3-4 g de alimento, mientras que un individuo adulto de $R$. norvegicus requiere alrededor de $25 \mathrm{~g}$ (Priotto \& Steinmann, 2003), por lo que es de esperar que un determinado hábitat soporte una mayor abundancia de M. musculus. Con respecto a $S$. hirsutus que tiene un peso corporal que oscila entre 20 y $206 \mathrm{~g}$ (Monge, 2008) es de esperar que el consumo diario sea superior a lo requerido por M. musculus, lo que también podría explicar la mayor abundancia del ratón casero.

En cuanto a la distribución de capturas en el tiempo, en el caso de $M$. musculus se concentró al inicio del estudio, en particular en los primeros seis meses, con el $70 \%$ de las capturas. Dado el mecanismo de colecta que implica la extracción de los individuos capturados, así como el efecto del control químico implementado durante el estudio por los encargados de la granja avícola puede explicar la disminución de la población para los últimos meses. Esta tendencia de capturas no fue claramente observada con las otras especies, dada su escasa presencia dentro de la granja avícola. En el caso de S. hirsutus, su abundancia fue relativamente baja dentro de la granja avícola, con respecto a lo observado en otros ambientes en el mismo sitio de estudio, en donde ha mostrado ser predominante (Monge-Meza, Herrera-Murillo \& AriasReverón, 2014), lo cual puede deberse a que el sistema de producción avícola podría no ofrecer los recursos suficientes de un hábitat adecuado para esta especie, comparado con un cultivo agrícola o un área con abundante vegetación herbácea. En cuanto a $R$. norvegicus es una especie poco común en el sitio, según estudios previos realizados en cultivos de maní (Monge, 2008; Monge, Chavarría \& Duverrán, 2010; Monge et al., 2014), así en el cultivo de maíz (datos no publicados del primer autor), en los cuales no había sido capturada. En este caso, dada la colindancia de la granja agrícola con usos semiurbanos, podría ser que esos sitios representen una fuente esporádica de colonización de la especie, y que su incursión a la granja no prosiga hacia otras áreas de la Estación Experimental.

En cuanto a los meses sin captura de M. musculus, lo cual ocurrió en particular en los meses de enero y febrero de 2012 y 2013, difiere a lo observado para las otras dos especies, ya que para el mes de enero del 2012 se logró el 22 y $33 \%$ de las capturas totales de S. hirsutus y $R$. norveguicus, respectivamente. Esta situación puede deberse a que estas últimas especies se encuentran en una incursión temporal en la granja avícola en una época que podría considerarse de escasez de recursos, al tratarse de la época seca en el sitio de estudio.

La estructura poblacional y la actividad reproductiva son dos aspectos que influyen en forma determinante en la dinámica poblacional de las especies. En este estudio, la proporción de machos de M. musculus duplicó a la de las hembras, lo que coincide con lo reportado por Kunimoto, De la Cruz, Arana \& Ramírez (2002) y las clases de mayor edad representaron un $60 \%$ de las capturas. 
Esta tendencia de más capturas de machos adultos puede deberse a que los machos adultos ocupan un ámbito de acción mayor que el de las hembras y el de los juveniles (Mikesic \& Drickamer, 1992), por lo que pueden estar expuestos a más estaciones de capturas. A su vez, la baja representatividad de individuos jóvenes puede deberse a que estos tienen una movilidad limitada alrededor de sus madrigueras hasta una edad de 14-16 días y son destetados a la edad de tres semanas cuando pesan aproximadamente $10 \mathrm{~g}$ (Berry, 1970), por lo que pueden estar presentes en el sitio, pero no son evidenciados a través de las capturas.

En cuanto a la proporción de hembras preñadas, de un $44 \%$ de hembras preñadas, es similar a lo estimado por King (1982) entre un 35 y 50\% de las hembras adultas, y Smith (1954) con un promedio de $46,8 \%$. El tamaño promedio de camada de 5,17 crías, coincide con lo encontrado por Meikle \& Drickamer (1986) entre 5,1 y 5,8, y similar a lo reportado por Smith (1954) con camadas entre 4,3 y 5,1 embriones.

Con respecto a la rata de campo (Sigmodon hirsutus) la proporción de sexos fue de 1,25:1 (machos:hembras), la cual es similar a la observada en un estudio previo en el sitio, de 1,4:1 (Monge 2008). La escasa captura de hembras no permitió definir una época de mayor actividad reproductiva para esta especie en la granja avícola.

La rata gris (R. norvegicus) a diferencia de las otras dos especies mostró una mayor proporción de hembras, en una relación 2:1 (hembras:machos), lo cual se explica por la organización social, dado que esta especie forma grupos familiares constituidos por un macho adulto, varias hembras adultas y numerosos animales inmaduros (Coto, 2007). Este resultado difiere de lo encontrado por Villa et al. (1997) quienes obtuvieron una mayor representación de machos, lo que atribuyen a una mayor movilidad de éstos, y por ende una mayor probabilidad a ser capturados; sin embargo, la baja captura de esta especie en este estudio limita definir tendencias poblacionales. La única hembra preñada tuvo una camada de 9 embriones, lo cual se encuentra dentro del ámbito de 1-15 embriones definido por Villa et al. (1997).

La información obtenida en este estudio permitió determinar las especies de roedores presentes en una granja avícola, así como su estructura poblacional y actividad reproductiva principalmente de la especie $M$. musculus, aspecto aún no documentado en Costa Rica.

\section{AGRADECIMIENTOS}

Los autores agradecen a J. Solano (Convenio UCRMAG) por las facilidades para realizar este estudio en la granja avícola de la Estación Experimental Agrícola Fabio Baudrit, y a E. Carrillo y otros revisores anónimos por la revisión del manuscrito. A la Vicerrectoría de Investigación de la Universidad de Costa Rica por el apoyo financiero a través del proyecto №813-B1-050.

\section{REFERENCIAS}

Berry, R. J. (1970). The natural history of the house mouse. Field Studies, 3, 219-262.

Bishop, J. A., \& Hartley, D. J. (1976). The size and age structure of rural populations of Rattus norvegicus containing individuals resistant to the anticoagulant poison warfarin. Journal of Animal Ecology, 45, 623-646. doi:10.2307/3572

Chou, C. W., Lee, P. F., Lu, K. H., \& Yu, H. T. (1998). A population study of house mice (Mus musculus castaneus) inhabiting rice granaries in Taiwan. Zoological Studies, 37, 201-212.

Coto, H. (2007). Actualización en biología y control de ratas sinantrópicas. Buenos Aires, Argentina: Grupo Editorial Gestalt.

Elias, D. J., \& Fall, M. W. (1988). The rodent problem in Latin America. In Prakash, I. (ed.), Rodent pest management. Florida, EEUU: CRC Press, Inc.

Gómez V. I. E., Bilenca, D. N., Cavia, R., Mino, M. H., Cittadino, E. A., \& Busch, M. (2001). Environmental factors associated with rodent infestations in Argentina poultry farms. British Poultry Science, 42, 300-307. doi:10.1080/00071660120055241

Villafañe, I. G., Cavia, R., Busch, M., \& Bilenca, D. N. (2003). Intrafarm variation of rodent infestations on poultry farms of central Argentina. British Poultry Science, 44, 669-673. Doi:10.1080/00071660210001643642

Gómez, V. I. E. G., Miñarro, F., Ribicich, M., Rossetti, C. A., Rossotti, D., \& Busch, M. (2004). Assessment of the risks of rats (Rattus norvegicus) and opossums (Didelphis albivesntris) in different poultry-rearing areas in Argentina. Brazilian Journal of Microbiology, 35, 359-363. doi: 10.1590/ S1517-83822004000300017

Gómez, V. I. E. G., Miñarro, F., Valenzuela, L. \& Bilenca, D. N. (2009). Experimental assessment of rodent control on two poultry farms of central Argentina. Journal of Applied Poultry Research, 18, 622-629. doi:10.3382/ japr.2008-00120 
Gómez V., I. E., \& Busch, M. (2007). Spatial and temporal patterns of Brown rat (Rattus norvegicus) abundance variation in poultry farm. Mammalian Biology, 72, 364-371. doi:10.1016/j.mambio.2006.09.002

Gratz, N. G. (1994). Rodents as carries of disease. In Buckle, A.P.; Smith, R.H., (eds.), Rodent pest and their control. United Kingdom: CABI International.

Greaves, J. H. (1984). La lucha contra los roedores en la agricultura. Roma, Italia: Organización de las Naciones Unidas para la Agricultura y la Alimentación (FAO).

Kandhwal, S. (2009). Evaluation of bait carrier for Rattus rattus L. infesting commercial poultry facilities in India. A step toward sustainable poultry management. International Journal of Art and Sciences, 3, 50-60.

King, C. M. (1982). Age structure and reproduction in feral New Zealand populations of the house mouse (Mus musculus), in relation to seedfall of southern beech. New Zealand of Zoology, 9, 467-480. doi:10.1080/03014223. 1982.10423879

Kunimoto, C., De la Cruz, C., Arana, M., \& Ramírez, O. E. (2002). Observaciones sobre la ecología poblacional del ratón doméstico en Lachay, Perú. Bulletin de I'Institut Français d'Études Andines, 31,323-328. doi:10.4000/bifea.6753

León, V., Guidobono, J., \& Busch, M. (2007). Abundancia de Mus musculus en granjas avícolas: efectos locales vs. efectos espaciales. Ecología Austral, 17,189-198.

Meikle, D. B., \& Drickamer, L. C. (1986). Food availability and secondary sex ratio variation in wild and laboratory house mice (Mus musculus). Journal of Reproduction and Fertility, 78, 587-591. Doi:10.1530/jrf.0.0780587. doi:10.2307/2426319

Mikesic, D. G. \&. Drickamer. L. C. (1992). Factors affecting home-range size in house mice (Mus musculus domesticus) living in outdoor enclosures. The American Midland Naturalist, 127, 31-40. doi:10.1080/09670870601105949

Miño, M. H., Cavia, R., Gómez, I. E., Bilenca, D. N., \& Busch, M. (2007). Seasonal abundance and distribution among habitats of small rodents on poultry farms. A contribution for their control. International Journal of Pest Management, 53,311-316.

Monge, J. (2008). Estructura poblacional y actividad reproductiva de la rata de campo (Sigmodon hirsutus) durante un ciclo de producción de maní (Arachis hypogaea) en Costa Rica. Agronomía Costarricense, 32(3), 161-167.

Monge, J., Chavarría, A., \& Duverrán, E. (2010). Comunidad de arvenses en un cultivo de maní (Arachis hypogaea) y su relación con la rata Sigmodon hirsutus en Alajuela, Costa Rica. Agronomía Costarricense, 34, 65-75.
Monge-Meza, J., Herrera-Murillo, F., \& Arias-Reverón, J. (2014). Daños de la rata Sigmodon hirsutus (Rodentia:Cricetidae) al cultivo de maní (Arachis hypogaea) en Alajuela, Costa Rica. UNED Research Journal, 6(1), 81-86. doi: 10.22458/ urj.v6i1.318

Parshad, V. R.; Ahmad, N., \& Chopra, G. (1987). Deterioration of poultry farm environment by commensal rodents and their control. International Biodeterioration, 23, 29-46. doi:10.1016/0265-3036(87)90040-6

Priotto, J., \& Steinmann, A. (2003). Biología de los roedores. En: Fundación Mundo Sano, Instituto Nacional de Enfermedades Virales Humanas y Grupo de Investigación en Ecología de Poblaciones (GIEP) de la Universidad Nacional de Río Cuarto. Manual de control de roedores en municipios. Publicación monográfica. Recuperado de http://www.bvsde.paho.org/bvsacd/ cd30/roedores/roedores.html

Ruscoe, W. A., Wilson, D., McElrea, L., McElrea, G., \& Richardson, S. J. (2004). A house mouse (Mus musculus) population eruption in response to rimu (Dacrydium cupressinum) seedfall in southern. New Zealand Journal of Ecology, 28, 259-265.

Singleton, G. R. (1985). Population dynamics of Mus musculus and its parasites in mallee wheatlands in Victoria during and after a drought. Australian Wildlife Research, 12, 437445. doi:10.1071/WR9850437

Smith, W. W. (1954). Reproduction in the house mouse, Mus musculus L., in Mississippi. Journal of Mammalogy, 35, 509-515. doi:10.2307/1375574

Sridhara, S., \& Krishnamurthy, T. R. (1992). Population dynamics of Rattus rattus in poultry and implications for control. In Borrecco, J. E.; Marsh, R. E. (eds), Proc. 15th Vertebrate Pest Conference. California, EEUU: University of California.

Villa C. B., Whisson, D. A., \& Sánchez-Cordero, V. (1997). Capture rate and reproductive patterns of Norway rats (Rattus norvegicus) (Muridae:Rodentia) in a poultry farm in Mexico City. Anales del Instituto de Biología, Universidad Nacional Autónoma de México. Serie Zoología, 68, 165-172.

WingChing-Jones, R., Monge-Meza, J., \& Pérez-Salas, R. (2009). Roedores pequeños en un sistema de producción de ganado lechero. Agronomía Mesoamericana, 20, 127133. doi:10.15517/am.v20i1.4988

Ylönen, H., Jacob, J., Davies, M., \& Singleton, G. (2002). Predation risk and habitat selection of Australian house mice Mus domesticus during an incipient plague: Desperate Behaviour due to food depletion. Oikos, 99, 284-289. doi:10.1034/j.1600-0706.2002.990208.x 